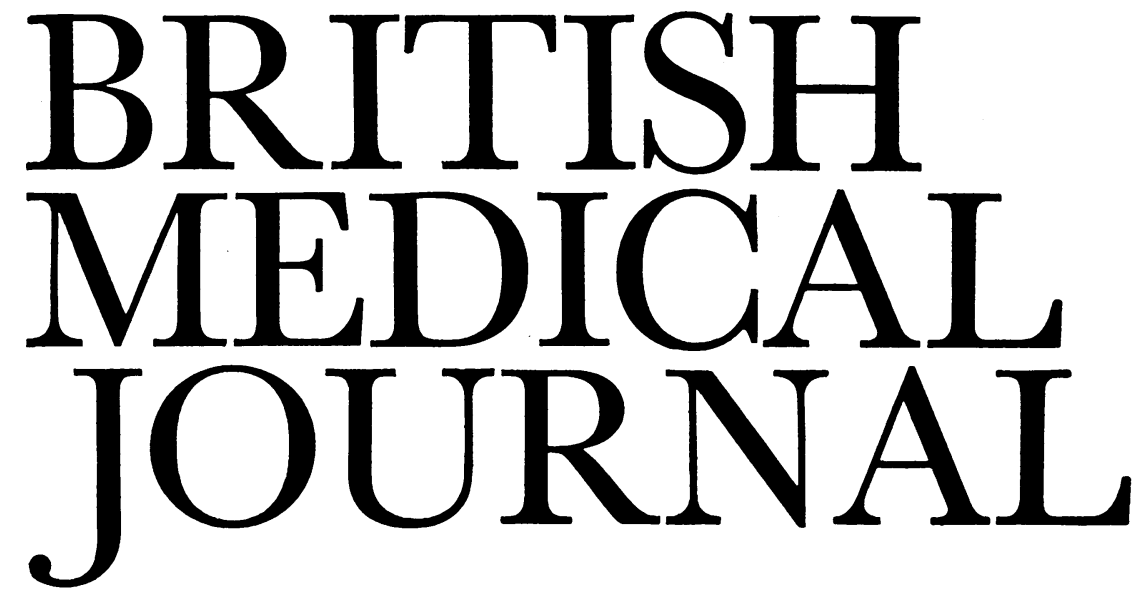

LONDON, SATURDAY 16 AUGUST 1980

\title{
Heart disease in different ethnic groups
}

A question on ethnic origins in a pilot study for the 1981 National Census was so badly answered that it will not now be used-so disappointing researchers interested in ethnic differences in susceptibility to coronary heart disease, for census data can provide denominators for incidence studies. Variations in the incidence of coronary heart disease by person and by place have long been used to generate and to test aetiological hypotheses. Large differences between national groups can be attributed to environmental factors, to genetic susceptibility, or to local diagnostic fashions. When one ethnic group has migrated to several contrasting geographical areas, or different ethnic groups are found within one locality, the number of variables is reduced, and the possibilities of distinguishing the effects of nature and nurture should be enhanced. Migrant studies along these lines have shown that the Japanese in California have more coronary disease than those in Hawaii, who in turn have more than those in Japan itself. ${ }^{1}$ Yemeni Jews appear to. develop coronary disease after migration to Israel. ${ }^{2}$ Nevertheless, while these studies show the importance of environmental factors they do not prove that the susceptibility of all races to coronary disease is identical. What evidence is there for ethnic differences within one country?

The province of Manitoba in Canada contains numerous first-generation and second-generation migrants from different European countries. Until 1966 both the place of birth and the ethnic origin (of the father) were available on death certificates and at census, so that standardised mortality ratios for coronary heart disease could be calculated for the years 1960-2 for different migrant groups. ${ }^{3}$ For first-generation male immigrants the highest standardised mortality ratios were found in Irishmen, followed by Scots, Welsh, English, East Europeans, and Scandinavians. When ethnic origin was used to include Canadian-born men a similar pattern emerged except that standardised mortality ratios in Jews, who were defined as a separate group, were highest; that in the native Indians came lowest. Unstandardised mortality figures from South Africa also suggest a high rate for Jews, those in Johannesburg having twice the crude mortality rate for ischaemic heart disease of the non-Jewish (presumably white) population. ${ }^{4}$

In Britain evidence for ethnic differences has come from the Tower Hamlets study of 1970-2, in which the age-standardised rate for coronary attacks in Asian immigrants in East London was found to be some $130 \%$ of that of the London born, while the rate in immigrants from the Caribbean was very low. ${ }^{56}$ These findings have more recently been confirmed nationally for deaths, by relating place of birth on death certificates to the census denominator, and extended to include European-born migrants to Britain. ${ }^{7} 8$ Further reports may be expected, but denominators will now be available only for the migrant generation.

What do the ethnic differences mean? They provide ammunition for champions of a large genetic component in coronary disease (though this makes bad news for the British, since eight of the 10 countries with the highest coronary rates are English speaking ${ }^{9}$ ). The answer may well be more complicated. Recent migrants from one country congregate together, sharing the same social and dietary habits and occupying particular jobs, which will differ from those of the host population and those of other migrant groups. The effects of these environmental factors are difficult to control for in studies, though socioeconomic differences could have accounted for the excess mortality in Jews in Manitoba. ${ }^{3}$ Perhaps the best controlled study of this kind was done among Italian and Jewish clothing workers in New York in the 1950s. ${ }^{1011}$ The two groups were similar in age, sex, occupation, socioeconomic status, body weight, and blood pressure, but the prevalence of coronary disease was twice as high in the Jews, who also had serum cholesterol concentrations some $15 \%$ higher than the Italians. Dietary intakes of energy and fats were similar, though the Jews obtained more from animal sources; and, though environmental factors in adult life were similar, those in early childhood (before immigration) must have been very different.

Ethnic differences in disease therefore present a tantalising source of aetiological information. The immigrant displays differences which might be attributable to genetic susceptibility, to early environment, or to the continuation of distinct traditional habits. A generation or so later immigrants' descendants may be so well integrated that much of any remaining differences might well be genetic, but the more complete the integration the greater the practical, ethical, and political problems of attempting to define those variations.

\footnotetext{
${ }^{1}$ Marmot M, Syme SL, Kagan A, Kato H, Cohen JB, Belsky J. Epidemiologic studies of coronary heart disease and stroke in Japanese men living in Japan, Hawaii, and California; prevalence of coronary and hypertensive heart disease and associated risk factors. Am $\mathcal{F}$ Epidemiol 1975;102: 514-25.
} 
2 Medalie JH, Kahn HA, Neufeld HN, et al. Myocardial infarction over a five-year period-1. Prevalence, incidence and mortality experience. fChronic Dis 1973 ;26:63-84.

3 Abu-Zeid HAH, Maini KK, Choi NW. Ethnic differences in mortality from ischaemic heart disease: a study of migrant and native populations. f Chronic Dis 1978 ;31:137-46.

4 Walker ARP, Segal I, Gilat T, Horowitz C. Excessive proneness of Jews to ischemic heart and bowel diseases. Am Heart F 1980;99:130-1.

5 Tunstall Pedoe H, Clayton D, Morris JN, Brigden W, McDonald L. Coronary heart attacks in East London. Lancet 1975 ;ii :833-8.

6 Tunstall Pedoe H. Uses of coronary heart attack registers. Br Heart $\mathcal{F}$ 1978;40:510-5.

7 Adelstein AM. Current vital statistics: methods and interpretation. $\mathrm{Br}$ Med F 1978;ii:983-7.

${ }^{8}$ Marmot MG, Adelstein A, Bulusu L. Cardiovascular mortality among migrants in England and Wales. Eighth European Congress of Cardiology, Paris 1980. Abstract 2877.

9 Tunstall Pedoe H. Atheroma. Medicine (Oxford) 1979; No $21: 1071-80$.

10 Epstein FH, Arbor A, Boas EP, Simpson R. The epidemiology of atherosclerosis among a random sample of clothing workers of different ethnic origins in New York City. 1. Prevalence of atherosclerosis and some associated characteristics. $\mathcal{F}$ Chronic Dis 1957;5:300-28.

${ }^{11}$ Epstein FH, Simpson R, Boas EP. Relation between diet and atherosclerosis among a working population of different ethnic origins. Am $\mathcal{F C l i n}$ Nutr 1956;4:10-9.

\section{Vaginal bleeding in early pregnancy}

How many women have an episode of threatened abortion during pregnancy? Figures as high as $20 \%{ }^{1}$ and as low as $2 \cdot 4 \%{ }^{2}$ have been quoted. Nevertheless, the reported incidence of at least $16 \%$ quoted by Hertig and Livingstone ${ }^{3}$ some 35 years ago is probably still correct today-and with women becoming more aware of potential dangers to the fetus fewer episodes will go untreated. So not surprisingly threatened abortion is one of the commonest causes for the admission of young women to hospital.

In general, admission to hospital for threatened abortion is confined to women with heavy or prolonged bleeding, and their natural worry is that they will lose their baby. That fear is well founded: in the circumstances $50-60 \%$ of women do abort spontaneously. ${ }^{4} \mathrm{~A}$ second worry for the woman who has bled is that if her pregnancy continues she may have an abnormal baby. Nevertheless, while some studies have shown an increase in congenital anomalies ${ }^{6}$ and epilepsy, ${ }^{7}$ the patient can take heart from a recent study ${ }^{8}$ from California which showed no statistically significant increase in fetal congenital anomalies where the pregnancy had been complicated by vaginal bleeding in the first or second trimester.

Other findings in that study would, however, give the patient cause for concern. The retrospective analysis of more than 25000 deliveries showed that the outcome of pregnancy was "suboptimal" twice as frequently when a threatened abortion had occurred. The incidence of prematurity was increased, as were those of low birth weight, breech delivery, and perinatal death. The outcome of pregnancy was related to the severity of early bleeding: a suboptimal outcome occurred in $30 \%$ of deliveries when this had been heavy and in only $19 \%$ when it had been light. Threatened abortion was not associated with an increased incidence of pre-eclampsia.

A possible criticism of the study is that the incidence of threatened abortion in the series was remarkably lowonly $1 \%$-suggesting that the sample may have been biased towards women with heavy bleeding or a history of complications in a previous pregnancy, and, therefore, more likely to have a suboptimal outcome in their current pregnancy.
Other studies have suggested that threatened abortion does not predispose to pregnancy complications, ${ }^{9}$ and that in some cases the bleeding may be regarded as physiological ${ }^{10}$; even so the balance of opinion is that threatened abortion is harmful. Furthermore, apart from increasing the incidence of perinatal death, ${ }^{11}$ it may possibly be associated with more subtle complications such as psychomotor retardation ${ }^{6}$ or psychological abnormalities ${ }^{12}$ presenting in childhood.

As the pathogenesis of threatened abortion is obscure and as there are no effective treatments, the best defence for the prudent obstetrician is an awareness of the potential hazards for the continuing pregnancy, which should be regarded as "at risk." Where the dates are uncertain the gestational age should be assessed by ultrasound. The patient should be booked for confinement at a specialist unit and, ideally, she should receive her antenatal care at hospital. In the third trimester, probably the fetal wellbeing should be monitored by serial estimations of oestrogen concentration, ultrasonography, and, in selected cases, antenatal cardiotocography. This may lead to the recognition of a compromised fetus and so to early delivery. Even when all seems well many obstetricians would advocate induction of labour at term. Threatened abortion may be unavoidable, but good antenatal care can minimise its effects.

${ }^{1}$ Niswander K, Gordon M. The Collaborative Perinatal Study: the women and their pregnancies. Philadelphia: WB Saunders, 1972.

2 Butler NR, Bonham DG. Perinatal mortulity: the first report of the 1958 British Perinatal Mortality Survey. Edinburgh: E and S Livingstone, 1963.

${ }^{3}$ Hertig AT, Livingstone RG. Spontaneous, threatened and habitual abortion: their pathogenesis and treatment. $N$ Engl f Med $1944 ; 230$ : 797-806.

4 Johannsen A. The prognosis of threatened abortion. Acta Obstet Gynecol Scand 1970;49:89-93.

5 Garoff L, Seppala M. Prediction of fetal outcome in threatened abortion by maternal serum placental lactogen and alpha fetoprotein. $A m \mathcal{F}$ Obstet Gynecol 1975;121:257-61.

${ }^{6}$ Ornoy A, Benady S, Kohen-Raz R, Russell A. Association between maternal bleeding during gestation and congenital anomalies in the offspring. Am $\mathcal{F}$ Obstet Gynecol 1976;124:474-8.

${ }^{7}$ Lilienfeld AM, Pasamanick B. Association of maternal and fetal factors with the development of epilepsy. 1. Abnormalities in the prenatal and perinatal periods. $\mathcal{F} A M A$ 1954;155:719-24.

${ }^{8}$ Funderburk SJ, Guthrie D, Meldrum D. Outcome of pregnancies complicated by early vaginal bleeding. Br F Obstet Gynaecol 1980;87:100-5.

${ }^{9}$ Gordon YB, Lewis JD, Pendlebury DJ. Is measurement of placental function and maternal weight worth while? Lancet 1978;i :1001-3.

10 Speert H, Guttmacher AF. Frequency and significance of bleeding in early pregnancy. $\mathcal{F} A M A 1954 ; \mathbf{1 5 5}: 712-5$.

11 Peckham $\mathrm{CH}$. Uterine bleeding during pregnancy. 1. When not followed by immediate termination of pregnancy. Obstet Gynecol 1970;35:937-41.

12 Bishop EH, Israel SL, Briscoe CC. Obstetric influences on the premature infant's first year of development. A report from the collaborative study of cerebral palsy. Obstet Gynecol $1965 ; 26: 628-35$.

\section{Electricity and bones}

Harnessing the silent and invisible power of electricity for medical treatment has attracted patients and doctors alike since the nineteenth century. Unfortunately, empiricism and charlatanry greatly discredited such brands of the Gilbertian magic lozenge, so that the recent revival of interest in the connection between electricity and bone metabolism has also aroused some suspicion. Advertisements are now appearing in orthopaedic journals for electric devices to aid the union of fractures. What is the basis of these claims ?

The piezo-electric phenomenon in stressed bone ${ }^{1}$ helps to explain the formation of "non-fracture" callus in response to 